\title{
Numerical Simulation and Analysis of the forming process of an airplane frame part
}

\author{
ZHANG Ling -Yun ${ }^{1,}$, WANG Wen -Yuan ${ }^{1, b^{*}}$ \\ ${ }^{1}$ Key Laboratory of Fundamental Science for National Defense of Aeronautical Digital \\ Manufacturing Process, Shenyang Aerospace University, No.37 Daoyi South Avenue, Shenbei \\ New Area, Shenyang, China 110136 \\ azhangly79@163.com, bwwy.2008@163.com
}

Keywords: Airplane frame parts; Drop hammer forming; Transition mould; Simulation Abstract: Airplane frame parts can form by the method of increasing the transition mould. The main purpose of the transitional surface design is to change the material flow state, and make the material flow is uniform. Mainly studied forming process to a typical frame sheet metal part, analyzed the forming characteristics, as well as the advantages and disadvantages of drop hammer forming, studied the transitional surface design, analyzed the wrinkling and rupture caused by a variety of reasons, finally designed a reasonable transition mould. The forming process of product has carried on the simulation by PAM-STAMP software, optimize the process parameters, verified the method is feasible.

\section{Introduction}

There are a lot of sheet metal parts in aircraft structure, airplane frame part is a kind of typical sheet metal parts. The characteristic is that the size of the parts structure is very widely, structure shape is complicated, it is easy to appear wrinkling and rupture when forming, thickness and surface quality requirement is very strict after forming. At present in domestic aviation manufacturing enterprises, the main processing method of airplane frame parts is drop hammer forming, which is a kind of processing technology that the sheet metal will be pressed into the needed surface part by using of drop hammer impact. But in order to prevent wrinkling and fracture, we need to add auxiliary tools such as rubber mat and Interval knock as to achieve the purpose of wrinkling elimination according to specific situation. The degree of mechanization is not high, the product accuracy and surface quality is poorer, the springback is big, rejection rate is also high. With the continuous development of aviation manufacturing industry, the requirements of the aviation product's quality is becoming more and more high, it is necessary to improve the old process, increase the degree of mechanization, reducing the traditional craftsmanship, enhance the quality of our products and production efficiency. So it is especially important to look for processing method instead of artificial knock, and improve product quality, this is a big difficult problem faced by domestic aviation factory now.

In this paper, with an airplane frame type sheet metal parts for example, using the 3D design software CATIA to analyze the forming performance and design the mould structure, and through the PAM - STAMP professional sheet metal forming simulation software for stamping simulation. Finally the method is proved to be effective.

\section{Part description}

The material of this part is 5A02, its strength is low but high plasticity and suitable for manufacturing parts which have high plasticity process requirement, its material properties as shown in table 1. The thickness of the part is $0.8 \mathrm{~mm}$, the minimum radius is $4 \mathrm{~mm}$ and the maximum radius is $6.8 \mathrm{~mm}$, the detailed dimension as shown in figure 1 .

The parts forming difficulties:

1. It is easy to cause fracture due to material shortage between the two inner box bodies.

2. Because eight radius are very small and the depth of the parts is very high, the rounded corner area also easy to break. 
3. Sheet metal flange wrinkle easily, so reasonable blank-holder force is the key to solve the flange wrinkling.

Tab.1 The basic parameters of 5A02 material

\begin{tabular}{|c|c|c|c|c|c|c|c|}
\hline name & state & $\begin{array}{l}\text { Thickness } \\
(\delta / m m)\end{array}$ & $\begin{array}{l}\text { density } \\
\left(\rho / g / \mathrm{cm}^{3}\right)\end{array}$ & $\begin{array}{l}\text { Tensile strength } \\
\left(\sigma_{b} / M P a\right)\end{array}$ & $\begin{array}{c}\text { Elongation } \\
(\delta / \%)\end{array}$ & $\begin{array}{c}\text { Modulus of } \\
\text { elasticity } \\
(E / G P a)\end{array}$ & $\begin{array}{c}\text { Poisson's } \\
\text { ratio } \\
(\mu)\end{array}$ \\
\hline $5 \mathrm{~A} 02$ & $\mathrm{O}$ & 0.8 & 2.68 & 190 & 25.8 & 70 & 0.32 \\
\hline
\end{tabular}
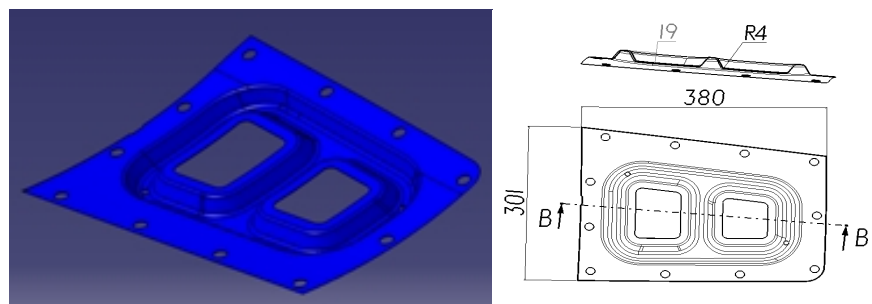

Fig.1 The airplane frame part and size

\section{Manufacturability analysis to the part forming}

This part can be seen as wide flange box made up by three small boxes, two small box bodies inside the outer one, the deep drawing direction of small box body and big box body is opposite. The radial of the flange material produce tensile stress ${ }^{\sigma}{ }_{1}$ and the tangential produce compressive stress $\sigma_{3}$ due to the function of drawing force. In under the joint action of ${ }^{\sigma_{1}}$ and $\sigma_{3}$, the metal materials of the flange area produce plastic deformation, material along the radial elongation and along the tangential compression, and constantly being pulled into the die participate in the forming of small box body inside. Box parts can be divided into straight sections and rounded corners, the rounded corner is a quarter of the cylinder, straight section is straight wall surface. Assuming the rounded part isn't connected to a straight part, the parts forming can be imagined as the bending of straight part and the drawing deformation of the rounded part. But in fact straight and round as a whole, there will be interaction and influence each other In the process of forming and no obvious boundaries between them.

According to theoretical analysis, as shown in figure 2, knowing that the parts drawing deformation has the following characteristics:

(1) The stress state of the flange deformation area is tensile stress and compressive stress.

(2) Along the blank on the surrounding the stress and strain distribution are uneven when the part drawing.

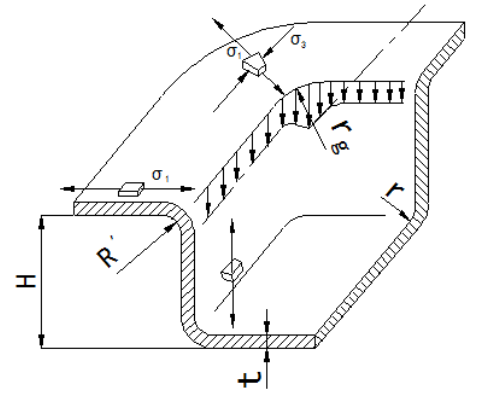

Fig.2 Stress distribution for a rectangular deep drawing part

(3) The degree of influence each other between of the straight edge deformation and rounded deformation depends on the relative radius $\left(r_{g} / B\right)$ and the relative height $(H / B)$. The smaller $r_{g} / B$ is, the greater the deformation influence of the Straight part on the rounded part. 


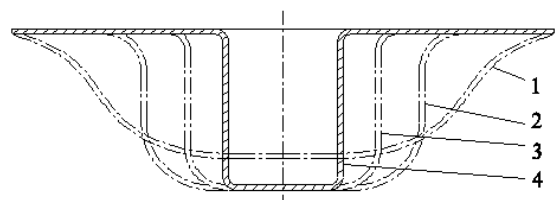

$1,2,3,4$ - Deep drawing step

Fig.3 Deep drawing method of the width of flange cylindrical parts

Based on the analysis of parts forming technology, decided to take deep drawing method of forming this parts for many times, as shown in figure 3. It is better to take a larger flange radius and bottom radius as soon as possible in the first drawing, the height of the part should be drawing to the required size, just need to decrease the radius and diameter of the cylindrical section in the later deep drawing process, the highly basically remain unchanged. Due to the material bending of the deformation area is lighter during the deep drawing, so the forming part surface is smooth and no crease.

First of all, the first transition mould are designed to determine whether can form the qualified part one time through simulation, if not, it must be designed more than two transition moulds. The role of transition mould can change the status of stored materials, can store more materials in the area where easy to fracture and reduce the storage materials in the area where prone to wrinkle, coupled with the appropriate smooth transition, the transition mode can solve the forming difficulties of the part eventually forming a qualified part meets the design requirements.

\section{Forming for once time}

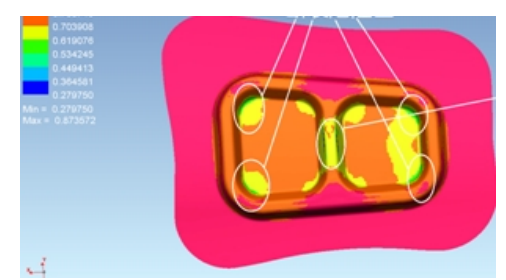

Fig.4 Fracture zone

The mould use common stamping die include the punch, die and blank holder ring. Stamping simulation is completed through the proper setting of process parameters. As shown in figure 4 is PAM-STAMP simulation results, simulation thickness nephogram shows the part has been broken, the fracture area is between the two small box bodies, and the proportion of the eight rounded corners. This is difficult to form a qualified part one time.

\section{Transitional surface design}

In order to solve the problem of the part forming, and through the above analysis of part forming performance, this paper will design a set of reasonable transitional surface. As shown in figure 5 is the die transitional surface and corresponding fillet dimension.

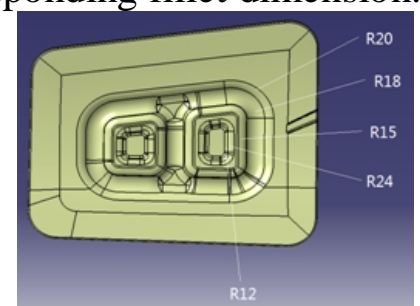

Fig.5 Transition surface of die and corresponding fillet dimension The design characteristics of transition mode:

1. The transitional surface curvature should be consistent with the original part surface curvature to reduce the difficulty of forming.

2. The big box body radius should be designed for bigger in order to make it easier for materials 
to flow inside to fill materials when forming transitional part.

3. The internal two small box bodies height should be appropriate to add some, not only can increase the storage material, but also conducive to form the smaller rounded corners.

4. Two reverse material storage tanks are designed respectively in the bottom surface of two small boxes.

5. Appropriately increasing the radius of mouth box, through simulation to determine the best combination.

Figure 5 marked the radius of each part of the transitional surface die, the size of the punch prepare according to the corresponding size of concave die, we can seen form the diagram that the smallest radius in feeding area in where the forming requirement is not high, other radius are much larger than the corresponding radius of final part, which played a transitional role very well.

\section{The finite element simulation}

Simulation of the first transition mould. The placement and the movement of the first transition die as follows: die fixed, sheet metal puts on the die, the blank-holder downward pressure sheet firstly, and then punch downward until the end of stamping. Process parameters also play a critical role for material forming, which will directly affect the forming results, through the analysis of the parts and the simulation contrast to optimize the process parameters, finally got a set of optimal process parameters. Parameter setting is that blank-holder force is $50 \mathrm{KN}$, stamping speed is 10 $\mathrm{mm} / \mathrm{ms}$, friction coefficient is 0.05 , the clearance between the punch and die is $0.88 \mathrm{~mm}$. As shown in figure 6 is the simulation result of transitional surface.

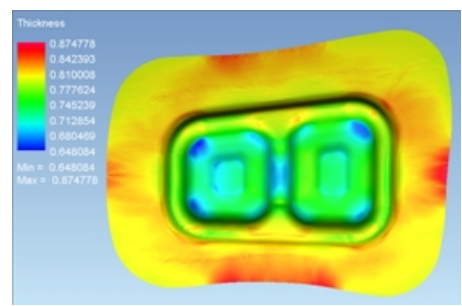

Fig.6 Transition mould thickness nephogram

As can be seen from the simulation result is that the thinning position of transitional part mainly is in eight rounded corners of the two small box bodies, but thinning amount less than the material permissible value. Material slightly wrinkled at the outside of the flange, because there is a trimming process in the last which can put severe wrinkling materials removed, the wrinkle area can not be considered. The thickness of the other areas also increased but be controlled in a reasonable range and meet the design requirements.

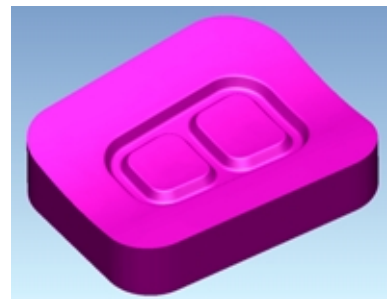

Fig.7 Drop pressing die

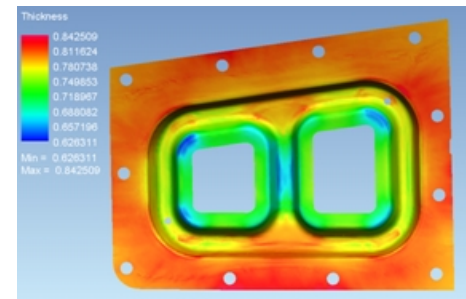

Fig.8 Final forming parts

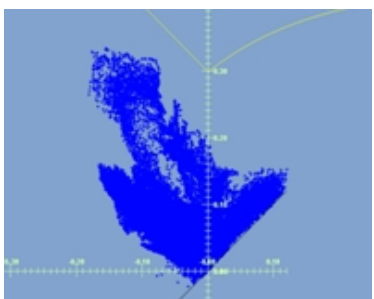

Fig.9 The FLD graph

Simulation of drop hammer forming. As shown in figure 7 above is drop hammer die, transitional plate is positioned on the die, the punch pressed transitional plate into the final shape of part, through the last trimming process, eventually forming the qualified product as shown in figure 8 . We can seen from the figure that the edge and corner in the middle of part thinning in amount, eight rounded corners are the most serious areas of thickness thinning, the biggest thinning rate was 
$21.7 \%$ less than the maximum permissible material thinning rate that was $25.8 \%$. At the same time Figure 9 forming limit diagram is pointed out that all areas of the parts in the safe area under curve. The qualified part is eventually manufactured by a transition mould and a drop hammer die. No need to design more transition mould, not only shorten the time of design and manufacturing and also reduce the unnecessary expenses.

\section{Conclusion}

1. Reasonable transition shape is the most important factor for quality and success of multichannel deep drawing. So designing a reasonable transitional surface is very important to ensure the quality of deep drawing stamping.

2. Stamping process is built on sheet metal plastic deformation, on the basis of grasping the accuracy of the material forming law, the paper analyzes the trend of the internal stress and strain to control material, effectively avoid sheet wrinkling and rupture.

3.Numerical simulation for forming process of product by using mature computer simulation technology, find out and modify the unreasonable structural design, greatly shorten the product manufacturing cycle, reduce a lot of mop die cost, improve the productivity.

4. This method has universal applicability to provide a valuable reference for other airplane frame parts processing, and has a guiding significance.

\section{References}

[1] Liang Bing-Wen, Hu Shi-Guang, Sheetmetal forming theory of plasticity, Mechanical industry Press, Beijing, 1987.

[2] Li Shuo-Ben, Stamping technology, Mechanical industry Press, Beijing,1982.

[3] Wang Jun-Biao, Jia Jian-Jun, Multi-channel time thinning Drawing Simulation and optimization Design, J. Journal of northwestern polytechnical university. 1997,15(03):348-354.

[4] Wang N M, Budiansky B, Analysis of sheet metal stamping by a finite element method, J. Journal of Applied Mechanics ASME. 1978, 100:73-82. 